\title{
Uso y aplicación de Nanopartículas de plata en Odontología
}

\author{
Use and application of silver nanoparticles in dentistry \\ Ana K. Bazán-Suarez ${ }^{a}$, Ana J. Monjáras-Avila ${ }^{b}$, \\ Carmen Balderas-Delgadillo ${ }^{c}$ y Eva M. Molina-Trinidad ${ }^{d}$
}

\begin{abstract}
:
The nanotechnology emerged in 1959 characterized by having a size from 1 to $100 \mathrm{~nm}$, this has been introduced in the health area seeking to develop new techniques in the treatments and in the transport of the medicine. In the area of the dentistry has been introduced the use of the NPs mainly based on silver in different materials whit in order to improve its proprieties, since it is well known that Silver has antibacterial effects and therebefore when applied to materials have better proprieties and results.
\end{abstract}

Keywords:

Nanoparticles, Ag, Silver, Dentistry, Uses, Application, Toxity, AgNPs.

\section{Resumen:}

La nanotecnologia surgió en 1959 caracterizada por tener un tamaño de 1 a $100 \mathrm{~nm}$, esto se ha introducido en el área de la salud buscando desarrollar nuevas técnicas en los tratamientos y en el transporte del medicamento. En el área de la odontología se ha introducido el uso de NPs principalmente a base de plata en diferentes materiales con el fin de mejorar sus propiedades, ya que es bien sabido que la Plata tiene efectos antibacterianos y por ello al ser aplicado en materiales de uso odontológico ayudan a que estos materiales tengan mejores propiedades y resultados.

Palabras Clave:

Nanopartículas, Ag, Plata, Odontologia, Usos, Aplicación, Toxicidad, AgNPs.

\section{Introducción}

La nanotecnología surge y es introducido en 1959 por Richard Feynman, lo que posteriormente lo llevó a ganar el premio nobel de física en 1965 y en 1986 Gerd Binning y Heinrich Rohrer diseñan y fabrican el microscopio de túnel, el cual tiene como objetivo poder visualizar los átomos como entidades independientes.

La US National Nanotechnology Initiative explica que "La nanotecnología es la comprensión de la materia que incluye imágenes, medidas, modelación, y manipulación de la materia a nano escala, donde los fenómenos únicos permiten nuevas aplicaciones". (1)

Una característica de los nanomateriales es su dimensión que está entre 1 y 100 nm (2), además tienen excelentes propiedades mecánicas, eléctricas, térmicas, ópticas, entre otras. (3)

Dependiendo a la dimensión, los nanomateriales se pueden clasificar en 4 tipos: (4)

Materiales de dimensión cero: son aquellas en que las tres dimensiones se ubican en el régimen nanométrico como los son las Nanopartículas NPs

\footnotetext{
a Autor de Correspondencia, Universidad Autónoma del Estado de Hidalgo, Instituto de Ciencias de la Salud, https://orcid.org/0000-00022400-5549, Email: karenbazann@gmail.com

b Universidad Autónoma del Estado de Hidalgo, Instituto de Ciencias de la Salud, https://orcid.org/0000-0002-5916-6510, Email: ana_monjaraz@uaeh.edu.mx

c Universidad Autónoma del Estado de Hidalgo, Instituto de Ciencias de la Salud, https://orcid.org/0000-0001-9654-5918, Email: carmenbd@uaeh.edu.mx

d Universidad Autónoma del Estado de Hidalgo, Instituto de Ciencias de la Salud, https://orcid.org/0000-0001-9654-5918, Email: emolinatrinidad@gmail.com
} 
1. Materiales de una dimensión: son de una dimensión con longitud variable y su dimensión sólo abarcó los nanómetros, como los nanoalambres y nanotubos.

2. Materiales de dos dimensiones: el área de espesor es indefinida pero su espesor va en orden de 1 a $100 \mathrm{~nm}$.

3. Materiales de tres dimensiones: son sólidos tridimensionales que están formados por unidades nanométricas.

Actualmente el uso de la nanotecnología en el área de salud ha dado pie al desarrollo de nuevas posibilidades en medicina y en odontología, siendo ahora más común su uso, está nanotecnología es aplicada principalmente en nuevas técnicas que buscan aliviar el dolor y otras que buscan desarrollar nano aparatos aptos para transportar medicamento mediante líquidos en el organismo humano. El propósito del uso de la nanotecnología aplicada en la odontología es el control, rastreo, construcción, reparación, protección y mejoramiento de la función bucal haciendo uso de sistemas nanométricos integrados a un dispositivo o a un medio biológico para realizar una acción determinada. (5)

\section{Procesos para la producción de Nanopartículas}

Existen diversas síntesis para la obtención de Nanopartículas como los métodos físicos, químicos y los biológicos, los dos primeros métodos implican el uso de diversos compuestos químicos, por ello estos métodos son más caros y dañinos para el medio ambiente, en cambio el método biológico es más amigable, rápido y menos costoso ya que solo se requiere de extractos de hojas.

Proceso mecánico-físico: basado en principios de la tecnología de microsistemas para obtener una molienda con forma y tamaño deseado.

> Proceso de fresado: Aplicado para la producción de nanomateriales metálicos cerámicos, en donde los materiales se trituran mediante fricción con molinos de alta energía compuestos de carburo de Wólfram - Acero. Este proceso produce estrés térmico permitiendo así tener un control de la forma de la partícula. (figura 1)

Proceso químico- físico: Basado en el proceso de organización molecular o atómica.

$>$ Proceso en fase gaseosa: Este proceso utiliza una fase gaseosa produciendo vapor del material usado mediante un proceso químico o físico, dependiendo del proceso el crecimiento de la Nanopartículas se da por condensación (gas a líquido), proceso de coagulación (adhesión de dos o más partículas) y de coalescencia (fusión de partículas). Estos procesos se utilizan en la elaboración de fullerenos y nanotubos de carbono. (figura 2)

Proceso en fase líquida: Se realizan en temperaturas más bajas que en la fase gaseosa.

> Proceso de precipitación: Realizado mediante iones metálicos, es decir, en reacciones de sales en disolventes, en donde se agrega un agente precipitante para obtener la partícula deseada, posteriormente pasa por un proceso de filtración y puede ser sometida a un tratamiento térmico. La morfología y el tamaño será determinado por la velocidad de reacción e influyen factores como la concentración del material, la temperatura, el pH, el orden de preparación y el mezclado de los materiales utilizados. (figura 3)

> Proceso sol-gel: Es un proceso químico-húmedo que se utiliza en la producción de nanomateriales porosos, polímeros cerámicos y en Nanopartículas de óxido. Para su elaboración se hace una dispersión de las partículas sólidas a un tamaño específico (1$100 \mathrm{~nm}$ ) distribuidas en agua o un disolvente orgánico que transformara el material en un gel para después transformarse en un material de óxido cerámico. (figura 4)
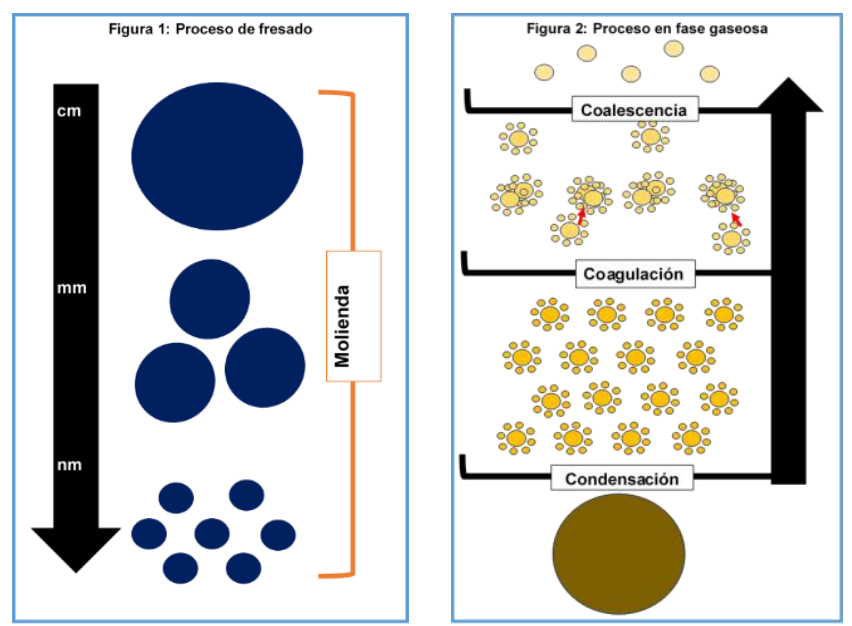

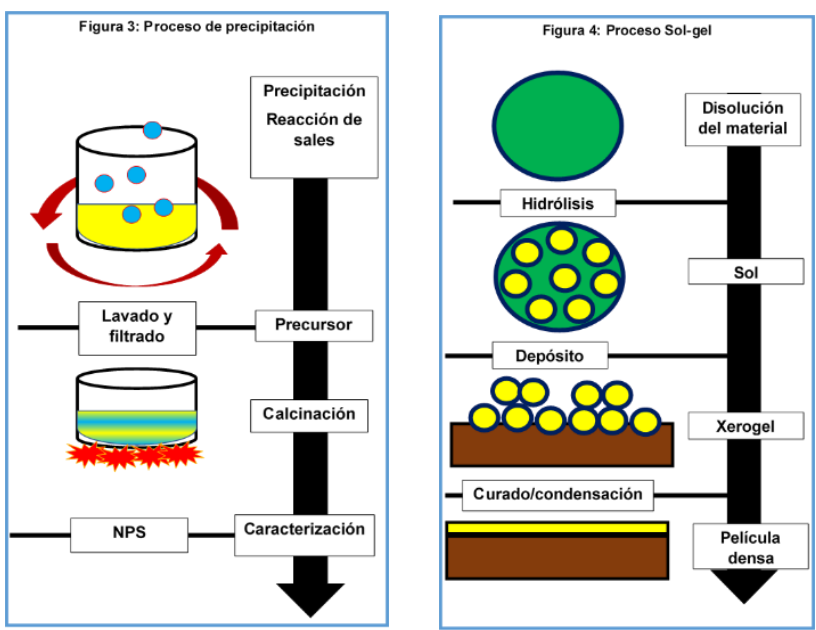

\section{Toxicidad de las AgNPs}

La toxicidad está determinada por la vía de exposición, absorción, transporte, distribución, acumulación en el organismo y el tipo de mecanismo de entrada a nivel celular.

Cuando las AgNPs son administradas por contacto dérmico, vía oral, inhalación o circulación sanguínea, pueden tener un nivel de toxicidad que depende de los iones de plata liberados, el tamaño, forma, solubilidad, la carga superficial y el estado de aglomeración que tengan, los efectos tóxicos se han observado más en las AgNPs de menor tamaño.

La toxicidad de las nanopartículas de plata (AgNPs) afecta principalmente a la mitocondria, ya que induce a la liberación mitocondrial del citocromo $\mathrm{c}$ al citosol, además provocan la pérdida del potencial de membrana mitocondrial dando como resultado la activación de la vía intrínseca de apoptosis. (6)

También se ha confirmado el poder genotóxico de las AgNPs a partir de ensayos in vivo e in vitro, observando roturas en el ADN posteriores a la exposición a estas.

Diferentes estudios realizados en ratones han demostrado que las AgNPs entran en la circulación sanguínea sin importar la vía de administración y se acumulan en los macrófagos para distribuirse a diversos órganos, es así que producen daño principalmente al hígado, riñón, corazón y bazo e incluso el cerebro y la piel, pero la gravedad de la afectación dependerá de la vía de administración. (7) En otro reporte (8), se menciona no haberse observaron cambios en los valores bioquímicos de la sangre ni cambios histopatológicos, sin embargo, se demostró que las AgNPs se acumularon en diversos órganos, coincidiendo el riñón, el cual es el principal órgano diana de las Nanopartículas, también el hígado, bazo, cerebro y pulmón.

\section{Mecanismo de acción bactericida de las AgNPs}

Se sabe que la producción de plata iónica es el resultado de la actividad antimicrobiana y se han descrito cuatro posibles mecanismos de acción. (9)

a) Primer mecanismo: los iones de plata interactúan para inhibir las enzimas de la célula bacteriana específicamente en el citocromo b, el citocromo d, entre el sitio de entrada de sustrato en la cadena respiratoria y la flavoproteína, en las regiones NADH y succinato deshidrogenasa y cuando la Ag se une al aminoácido cisteína provoca la muerte de la bacteria.

b) Segundo mecanismo: la plata iónica produce la ruptura de la pared celular inhibiendo el movimiento de la bacteria y del paso de nutrientes a ella, provocando así la muerte celular.

c) Tercer mecanismo : la interacción de la plata iónica afecta el ADN de la bacteria dando como resultado una mutación en su ADN y produciendo así su muerte celular.

d) Cuarto mecanismo : La plata se une a los radicales libres formados por el metabolismo aeróbico de la célula y al acumularse los radicales libres dentro de la bacteria rompen la membrana celular y de esta forma se produce la muerte de la bacteria.

\section{Aplicaciones de las AgNPs en Odontología}

La plata ha sido utilizada por muchos años debido a los efectos antimicrobianos que posee, aunque su uso sigue siendo tema de discusión por la toxicidad que genera esta partícula inclusive en bajas concentraciones, sin embargo, son más grandes los beneficios en cada área de aplicación lo que las hace potencialmente eficaces. (10) Con el tiempo se ha estudiado la forma de implementarlas para potenciar sus efectos en materiales restauradores dentales, como lo es la resina acrílica autopolimerizable, para la elaboración de aparatos de ortodoncia y en la resina acrílica termocurable, que es utilizada en la elaboración de las prótesis totales, buscando obtener sus beneficios en la base de esta aparatología y tipo de restauración dental que esta propensa a almacenar grandes cantidades de hongos y bacterias por la porosidad de su naturaleza y la zona utilizada por el portador, obteniendo una eficiente acción antimicrobiana, antifúngica y antiviral siendo proporcional a la cantidad de iones de plata liberados y su disponibilidad para interactuar con las membranas celulares microbianas.(10) De acuerdo a un reporte realizado en la revista Odontológica Mexicana, las Nanopartículas de plata incorporadas en retenedores acrílicos, con una 
concentración de 500 ppm y tamaño de 40 nm, presentaron un mayor efecto antimicrobiano contra $\mathrm{S}$. mutans y se demostró que presentaron alto potencial para resolver el problema de las bacterias multirresistentes a los antibióticos, ya que es poco probable que los microorganismos desarrollen resistencia contra la plata. (11)

Además se ha mostrado su eficacia en materiales dentales como nanocompuestos, monómeros de resina y adhesivos dentales, con el fin obtener su rendimiento sin intervenir en la resistencia de unión, contracción de polimerización y módulo elástico de la capa adhesiva (12), en el área de endodoncia, se han utilizado como medicación intraconducto y en soluciones irrigadoras por su efecto bactericida frente a E. Faecalis y eliminación de la capa de barrillo dentinario, exponiendo los túbulos sin afectar el sustrato dentinal, teniendo un efecto similar al hipoclorito de sodio (13) de igual manera como recubrimiento bacteriano para el titanio o en las matrices de los biomateriales cerámicos que conforman los implantes dentales disminuyendo el biofilm que en estos se genera y a la vez actúa como auxiliar en control de la periimplantitis, lo que ayuda a evitar una segunda intervención quirúrgica (14) y como parte de la nanotecnología se ha desarrollado nano-hueso que simula la estructura y composición ósea.

En el área de ortodoncia las AgNPs se ha aprovechado su efecto antimicrobiano en los retenedores ortodónticos convencionales que provocan la acumulación de placa dentobacteriana, ya que muestra una excelente actividad antimicrobiana como inhibidor del biofilm cariogénico, principalmente contra el Streptococcuss mutans que provoca a su vez la desmineralización del esmalte, además, se ha informado que las partículas de plata pueden inhibir las glicoltransferasas libres, enzimas responsables de promover la glucosa y la adhesión celular que permite la producción de glicanos y polisacáridos extracelulares (15), también se han reportado como auxiliares en el control del dolor en esta misma área durante el transcurso del tratamiento controlando la zona de dolor e incrementado la ramificación de las terminaciones nerviosas al utilizar nanoesferas que contienen factores de crecimiento que favorecen la regeneración del tejido nervioso. (5)

Este tipo de partículas han tenido un gran impacto y un destacado uso en el área de odontología como alternativa segura en empastes dentales, ya que poseen efectos antibacterianos, propiedades antifúngicas y anti desgaste.(5)

Por otro lado, es bien sabido que el tamaño de la Nanopartículas puede estar relacionada con la liberación de los iones de plata y la penetración al interior de la célula y así lograr una alteración metabólica para llevar a una muerte celular bacteriana.(16)
Además, este efecto protege el ambiente oral contra la proliferación excesiva de la flora bacteriana y ayuda a fortalecer la protección contra la caries dental.

Un estudio in vitro realizado en un período de 5 años (de 2012 a 2017) demostró que las AgNPs aportan conocimiento para el tratamiento de cáncer oral por sus excelentes propiedades antitumorales de (10) asociadas a su inducción de estrés oxidativo dando como resultado una genotoxicidad y una apoptosis del ADN. (17)

Otras propiedades de las AgNPs que están siendo implementadas en otras áreas de la odontología, consisten en la identificación de enfermedades mediante fluidos como lo es la saliva, o tejidos donde los nano dispositivos son capaces de realizar análisis a escala subcelular identificando y cuantificando moléculas toxicas, como el uso de NPs de oro que se han sometido a resonancias magnéticas para provocar un contraste entre las células cancerosas y las normales y así ser observadas en un microscopio confocal de reflectancia.(1)

\section{Conclusión:}

La nanotecnología aplicada en la salud ha representado un gran avance en la medicina y también en las diferentes áreas de la odontología donde ha tenido un gran impacto ya que ha revolucionado la forma en que se realizan los tratamientos cotidianos, mezclando diversas áreas de estudio con un mismo fin la aplicación de NPs en para mejorar las propiedades físico-químicas de los materiales dentales incrementando su eficacia y así obtener mejores resultados después de su aplicación.

Esta tecnología es considerada como algo innovador y prometedor en esta área, desde mejorar los métodos para un diagnóstico temprano y su tratamiento hasta la regeneración tisular en el área de la implantología en un menor tiempo.

La aplicación de la nanotecnología ha demostrado tener grandes avances en los últimos años y ha sido aplicada en biomateriales dentales de mayor uso, sin embargo, se necesitan más estudios clínicos a largo plazo para conocer los beneficios que implica su uso para poder mejorar y brindar una mejor calidad del tratamiento en este campo innovador. 


\section{Referencias}

Cantín L M, Vilos O C, Suazo G I. Nanoodontología: el Futuro de la Odontología Basada en Sistemas Nanotecnológicos. Int J Odontostomatol. 2010;4(2):127-32.

[2] Carmen Santisteban Trigo María Manuela Valverde Logotipo Título de la revista Juan Manuel García Arcos P, Hoyos Manchado Rafael Iigo Roció Escudero Ávila R, Maldonado Lasunción Javier Revello Sánchez Plantilla de la revista Norberto Díaz Díaz I, Deporte M, Grao Cruces MoleQla Ambiental A, Martín Calvo MoleQla Energía A, et al. MoleQla 26 Metodologias para el desarrollo de videojuegos. MoleQla [Internet]. 26. Disponible en: http://www.upo.es/MoleQla

[3] Navarro-Rosales M. Modificación Superficial por Plasma de Nanopartículas de Cobre y Preparación de Nanocompuestos por Fotocurado. Caracterización y Evaluación de sus Propiedades Antimicrobianas. 2012;

Gutiérrez CEW. Las NANOPARTÍCULAS: pequeñas estructuras con gran potencial ¿Por qué el interés en estos materiales? ¿Qué aplicaciones tienen? Contacto Nucl [Internet]. 2005;24-9. Disponible http://www.inin.gob.mx/publicaciones/documentospdf/39 NANOPARTICULAS.pdf

Garza G, Pozas A, Rivera G. Aplicación de la nanotecnología en odontología: Nano-odontología. CES Odontol. 2011;24(2):8791.

Aguiar N, Meira D, Raquel S. Study on the efficacy of the Portuguese cooperative taxation. REVESCO Rev Estud Coop. 2015;121(September 2015):7-32.

del Rocío E, Ávila L, Arroyo O. Las Nanopartículas De Plata: Mecanismos De Entrada, Toxicidad Y Estrés Oxidativo*. Rev Educ Bioquímica. 2017;36(2):39-54.

[8] Espinosa-Cristobal LF, Martinez-Castañon GA, LoyolaRodriguez JP, Patiño-Marin N, Reyes-Macías JF, VargasMorales JM, et al. Toxicity, distribution, and accumulation of silver nanoparticles in Wistar rats. J Nanoparticle Res. $2013 ; 15(6)$.

Fernández BT. Estudio de las aplicaciones biomédicas de las nanopartículas de plata. Univ Sevilla [Internet]. 2017;39. Disponible

https://idus.us.es/xmlui/bitstream/handle/11441/66375/Fernánde z Bueno\%2C Teresa.pdf?sequence=1\&isAllowed=y

López Flores AI, González Flores A. Efecto en la microdureza de resinas compuestas aplicando un recubrimiento de nanopartículas de plata inmersas en un adhesivo hidrofilico. [Toluca, México]: Universidad Autóonoma del Estado de México; 2018.

[11] de la Fuente Hernández J, Álvarez Pérez MA, Sifuentes Valenzuela MC. Uso de nuevas tecnologías en odontología. 2011;15:157-62.

[12] Torres Méndez F, Torres Gallegos I, Martinez-Castañon GA Zavala Alonso N, Patiño Marin N, Niño Martínez N, et al. Effects of silver nanoparticles on the bonding of three adhesive systems to fluorotic enamel. Dent Mater. 2017;36(3):266-74.

[13] Gonzales Luna P, Martínez Castañon G, Zavala Alonso N, Patiño Marin N, Niño Martínez N, Morán Martínez J, et al. Bactericide Effect of Silver Nanoparticles as a Final Irrigation Agent in Endodontics on Enterococcus faecalis: An Ex Vivo Study. 2016;(July).
[14] González Jiménez A, Fontecha AG. Utilización De Nanopartículas De Plata Como Agente Antibacteriano En Infecciones Óseas [Internet]. Universidad Computense; 2018. Disponible http://147.96.70.122/Web/TFG/TFG/Memoria/ADELA GONZALEZ JIMENEZ.pdf

[15] Freire P, Albuquerque A, Sampaio F, André G, Flores M, Stamford T, et al. AgNPs: The New Allies Against S . Mutans Biofilm - A Pilot Clinical Trial and Microbiological Assay. 2017;28:417-22.

[16] Gutiérrez D, Omar J, López R, Yobanny S, González C, Cornejo $\mathrm{D}$, et al. Evaluación del efecto antimicrobiano de las nanopartículas de plata en placa dentobacteriana aislada de pacientes. 2019;4(suppl 2):15-8.

[17] Noronha VT, Paula AJ, Durán G, Galembeck A, Cogo-Müller K, Franz-Montan M, et al. Silver nanoparticles in dentistry. Dent Mater [Internet]. 2017;33(10):1110-26. Disponible en: http://dx.doi.org/10.1016/j.dental.2017.07.002 